\title{
Investigation of GMAW by Simulation Modelling
}

\author{
Manahil Tongov \\ Faculty of Idustrial Technology \\ Technical University of Sofia \\ Center of Welding \\ Institute of Metal Science, Equipment \\ and Technologies with Hydro- \\ and Aerodynamics Centre "Acad. A. Balevski” \\ Bulgarian Academy of Sciences \\ Sofia, Bulgaria \\ tongov@tu-sofia.bg
}

\begin{abstract}
The thermal and deformation cycle during welding is directly reflected on the formation of the welded joint and the imperfections that can occur in any specific case. The simulation modelling of the heating and cooling processes makes it possible to determine the temporary and residual stresses in the welded joint. When solving the thermal and deformation tasks, it is essential to use data on the characteristics of the material in the entire temperature range in which the studied processes take place. At the same time, these data are often not available. In order to be able to use simulation solutions in practice, the standard EN ISO 18166 provides for calibration of thermal and deformation models before they are applied to the welded structure. In this study, the calibration of a thermal model applicable to MIG / MAG welding is considered. The heat source is superficial and axisymmetric. The calibration parameters are efficiency, effective radius of the heat source and coefficient determining the deviation from the normal central Gaussian distribution. Experimental data on the bead shape were used for the calibration process. The obtained simulation results for the temperature field are compared with the experimental ones. Sensitivity analysis of the solution with respect to the material characteristics was performed.
\end{abstract}

Keywords - GMAW; modelling; heat source; calibrating parameters; calibrating methods; sensitivity analysis.

\section{INTRODUCTION}

The bead formation during GMAW continues to be studied by different authors. Usually they investigate the welding process in different conditions, the used basic and auxiliary materials and protective media $[1 \div 7]$, [18]. In parallel, different methods are used to model thermal processes [8 $\div 17]$. As a result of the combination of the two approaches, conditions are created for predicting the temperature cycles and the development of the deformation processes during welding. In addition, solving the temperature problem makes it possible to trace the structural changes in the HAZ. For this purpose, the cooling time from 800 to $500\left[{ }^{0} \mathrm{C}\right]$ is normally used. Different heat source models are used in solving the heat problem. The ISO / TS 18166 standard requires that the heat source used be calibrated before it is applied to the specific welded structure. The model calibration procedure involves adjusting the parameters of the model in such a way that the obtained calculated results practically coincide with the experimentally measured ones. The comparison of the experimental and calculated results can be performed on the shape and dimensions of the melting zone and / or temperature cycles at points of the welded joint. The specimens used to carry out the experimental tests must be of the same material and of the same thickness as the welded structure. During the experiment, the same welding mode parameters (arc current and voltage, and welding speed, heating temperature, etc.) should be used as in the actual design. The process modeling must be performed with the dimensions and material of the welded plates both during the experiment and with the same welding mode. As data on the thermal properties of the material are often not available in the entire range of interest, the standard requires an sensitivity analysis of the solution to the input data. Within this study, a heat source model is proposed, applicable for GMAW 
with no inflection in penetration profile when the goal is analysis of the processes in the HAZ.

\section{HEAT SOURCE}

The proposed heat source is surface axisymmetric and is described by the equation:

$$
\begin{aligned}
& q(r)=q_{\text {eff }} \frac{A}{2}\left[\frac{1}{\sigma \sqrt{2 \pi}} \exp \left(-\frac{\left(r-r_{0}\right)^{2}}{2 \sigma^{2}}\right)+\right. \\
& \left.+\frac{1}{\sigma \sqrt{2 \pi}} \exp \left(-\frac{\left(r+r_{0}\right)^{2}}{2 \sigma^{2}}\right)\right]=q_{\text {eff }} A f(r)
\end{aligned}
$$

Here $q_{e f f}=\eta I_{w} U_{a}$ is the effective heat output determined by the efficiency, the magnitude of the welding current and the arc voltage; $f(r)$ is a heat flux distribution function and $\mathrm{A}$ is a norming multiplier to be determined by the condition $\int_{0}^{\infty} A f(r) 2 \pi r d r=1$. To solve the heat problem, the effective heating radius $r_{\text {arc }}$ and the coefficient of deviation of the heat source from a Gaussian heat source $\alpha_{\text {arc }}=r_{0} / r_{\text {arc }}$ are used. The efficiency and the specified parameters are calibrated with respect to the heat source. They express $q_{e f f}, r_{0}=\alpha_{\text {arc }} . r_{\text {arc }}$ and $\sigma=3 . r_{\text {arc }}$.

The calibration of the thermal model is performed by solving an optimization problem with respect to the obtained experimental results. As a result of the experiment, the width of the seam and the depth of the penetration are known. Simulation modeling of the welding process is performed, and the length of the seam must be sufficient to reach a quasi-stationary process. Based on the obtained solution, the temperatures at the points corresponding to the depth of penetration and the width of the seam - T1max and T2max. Thouse temperatures are determined by finding the maximum values along lines parallel to the weld axis and passing through the corresponding point of the seam cross section. Here it should be borne in mind that these two quantities are located in different sections perpendicular to the axis of the seam. As a target function in solving the optimization problem can be used

$$
\begin{aligned}
& \Phi\left(\eta, \alpha_{\text {arc }}, r_{\text {arc }}\right)=\left(\frac{T_{1 \mathrm{max}}-T_{S}}{T_{S}}\right)^{2}+ \\
& +\left(\frac{T_{2 \max }-T_{S}}{T_{S}}\right)^{2} \Rightarrow \min
\end{aligned}
$$

or

$$
\begin{aligned}
& \Phi\left(\eta, \alpha_{\text {arc }}, r_{\text {arc }}\right)= \\
& =\max \left(\left|\frac{T_{1 \text { max }}-T_{S}}{T_{S}}\right|,\left|\frac{T_{2 \text { max }}-T_{S}}{T_{S}}\right|\right) \Rightarrow \min
\end{aligned}
$$

As a result of solving the optimization problem, the calibration parameters are determined - the efficiency $(\eta)$, the effective radius of the heating spot $\left(\mathrm{r}_{\mathrm{arc}}\right)$, and the distribution coefficient $\left(\alpha_{\mathrm{arc}}\right)$. Since the functions of the form (2) and (3) are usually multi-extreme, the optimization problem itself is solved in two steps. In the first step, the Monte Carlo method and equation (3) are used. The obtained solutions are sorted by the value of the objective function. Within the second step, the five solutions with the best result from the first step are used as the starting point of the optimization process. The coordinate method and equation (2) are used. The final solution is the one that has the smallest value of the objective function within the second step of solving the optimization problem.

The experimental results used to calibrate the model were taken from [18]. The chemical composition of the base and filler metal is shown in Table 1 . The size of the samples is $20 \times 20 \times 100$ [mm]. Mode No. 3 is considered, in which welding speed $\mathrm{S}=50[\mathrm{~cm} / \mathrm{min}]$; arc voltage $\mathrm{U}=25$ [V]; welding current $\mathrm{I}=210$ [A] and shielding gas is $80 \%$ $\mathrm{Ar}+20 \% \mathrm{CO} 2$. The results obtained are a penetration depth of 1.75 [mm] and a seam width of 10.3 [mm]. The characteristic feature of this welding mode is that an initial process of formation of an inflection point in the penetration profile is observed.

TABLE I. CHEMICAL COMPOSITION OF THE BASE AND FILLER MATERIALS USED [18].

\begin{tabular}{|c|c|c|c|c|c|}
\hline \multirow{2}{*}{$\begin{array}{c}\text { alloying } \\
\text { element }\end{array}$} & \multicolumn{2}{|c|}{ quantity, } & \multirow{2}{*}{$\begin{array}{c}\text { alloying } \\
\text { wt \% }\end{array}$} & \multicolumn{2}{|c|}{$\begin{array}{c}\text { quantity, } \\
\text { wt \% }\end{array}$} \\
\cline { 2 - 3 } \cline { 6 - 6 } & $\begin{array}{c}\text { base } \\
\text { metal }\end{array}$ & $\begin{array}{c}\text { filler } \\
\text { metal }\end{array}$ & & $\begin{array}{c}\text { base } \\
\text { metal }\end{array}$ & $\begin{array}{c}\text { filler } \\
\text { metal }\end{array}$ \\
\hline $\mathrm{C}$ & $0.01 \div 0.03$ & 0.1 & $\mathrm{Cu}$ & 0.1 & \\
\hline $\mathrm{Si}$ & $0.08 \div 0.1$ & 0.5 & $\mathrm{Mo}$ & & 0.2 \\
\hline $\mathrm{Mn}$ & 0.2 & 1.1 & $\mathrm{~S}$ & 0.03 & 0.03 \\
\hline $\mathrm{Cr}$ & 0.1 & 0.5 & $\mathrm{P}$ & 0.04 & 0.03 \\
\hline $\mathrm{Ni}$ & 0.1 & 0.5 & & & \\
\hline
\end{tabular}

\section{RESULTS AND ANALYSIS}

When solving the problem within the first step of the optimization process, a result was obtained, which is partially shown in Table 2 . The results obtained by the second step of solving the optimization problem are shown in Table 3. Figure 1 shows the changes of the temperatures along the control lines at the last moment of the calculation to determine the calibration parameters.

The maximum width of the weld pool is at $x=47.2$ [mm] (Fig. 2). Along the seam axis, the liquid phase is in the range from 38.75 to 53.5 [mm] (Fig. 3). The length of the weld pool is 14.75 [mm]. To determine the shape of the weld, isotherms are constructed in planes perpendicular to the axis of the seam within the range of the weld pool (Fig. 4). The shell of these curves is the shape of the penetration. It is compared with the experimental results (Fig. 5).

TABLE II. SORTED RESULTS AFTER THE FIRST STEP OF SOLVING THE OPTIMIZATION TASK.

\begin{tabular}{|c|c|c|c|c|}
\hline No & $\boldsymbol{\eta}$ & $\boldsymbol{\alpha}_{\text {arc }}$ & $\mathbf{r}_{\text {arc }}$ [mm] & Objective \\
\hline 1 & 0,8193517 & 0,20913114 & 9,51173436 & 0,01235520 \\
\hline 2 & 0,7976760 & 0,25520187 & 8,52934354 & 0,02154287 \\
\hline 3 & 0,8379909 & 0,24528641 & 9,57802056 & 0,03259657 \\
\hline 4 & 0,8096316 & 0,28211004 & 9,09826960 & 0,03995324 \\
\hline 5 & 0,7530350 & 0,29744560 & 8,34357737 & 0,04594332 \\
\hline 6 & 0,7943647 & 0,26286507 & 7,78115176 & 0,05681203 \\
\hline
\end{tabular}


Environment. Technology. Resources. Rezekne, Latvia Proceedings of the $13^{\text {th }}$ International Scientific and Practical Conference. Volume 3, 357-362

\begin{tabular}{|c|l|l|l|l|}
\hline 7 & 0,8040391 & 0,27428205 & 7,51426740 & 0,07803883 \\
\hline 8 & 0,7155430 & 0,25551316 & 8,67656483 & 0,08982455 \\
\hline 9 & 0,8470320 & 0,06620380 & 9,7889645 & 0,09321748 \\
\hline 10 & 0,8364268 & 0,03385723 & 9,64293343 & 0,10103100 \\
\hline
\end{tabular}

TABLE III. RESULTS OF THE SECOND STEP OF CALIBRATION OF THE HEAT SOURCE MODEL..

\begin{tabular}{|c|c|c|c|c|}
\hline $\begin{array}{c}\text { No of } \\
\text { start } \\
\text { point }\end{array}$ & $\boldsymbol{\eta}$ & $\boldsymbol{\alpha}_{\text {arc }}$ & $\mathbf{r}_{\text {arc }}$ [mm] & Objective \\
\hline 1 & 0,81935 & 0,21393 & 9,5117 & $1,09 \mathrm{E}-006$ \\
\hline 2 & 0,7978 & 0,27797 & 8,512 & $1,04 \mathrm{E}-006$ \\
\hline 3 & 0,81422 & 0,20457 & 9,578 & $6,67 \mathrm{E}-007$ \\
\hline 4 & 0,82587 & 0,23711 & 9,0983 & $4,88 \mathrm{E}-006$ \\
\hline 5 & 0,80707 & 0,28622 & 8,3436 & $1,06 \mathrm{E}-005$ \\
\hline
\end{tabular}
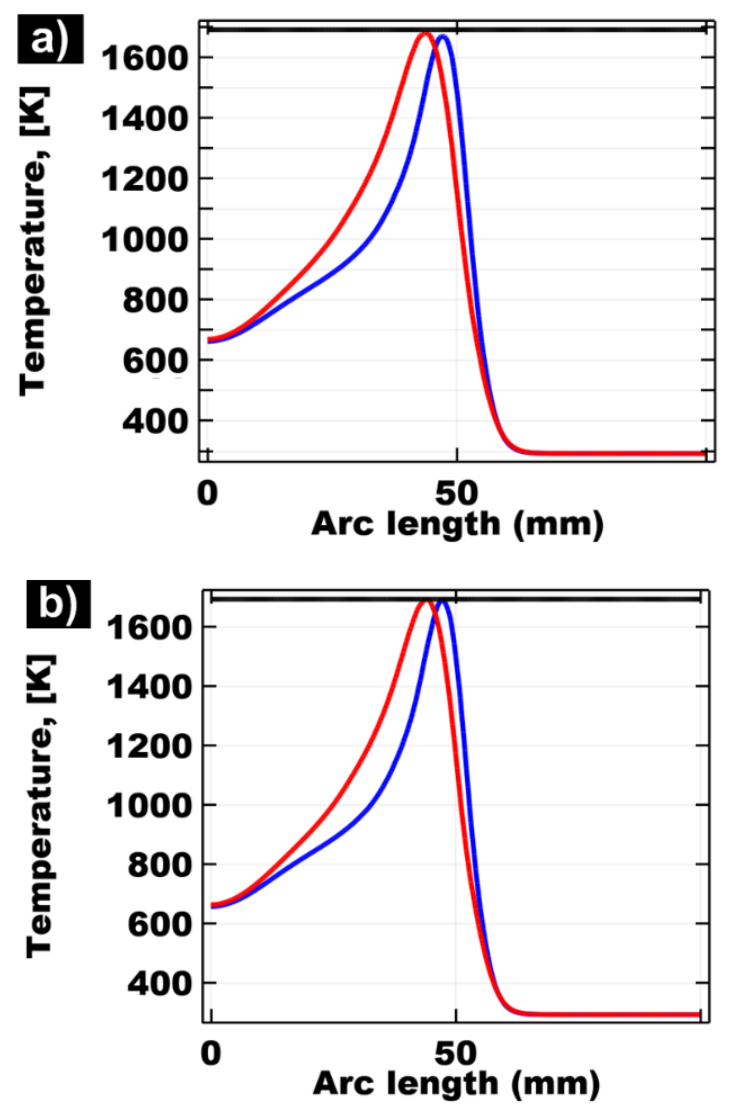

Fig.1. Results of solving the optimization problem: after the first step of the optimization process (a) and after the second step at starting point No. 3 (b).

It can be seen that in terms of the depth of penetration and the width of the bead, the model describes the wellobtained experimental shape. At the same time, the calculated form of penetration deviates from the experimentally obtained one. This confirms the fact that for seams with inflection in the form of penetration it is more appropriate to use models of heat sources combining surface and bulk heat source. An extreme example in this regard is electron beam welding [19].
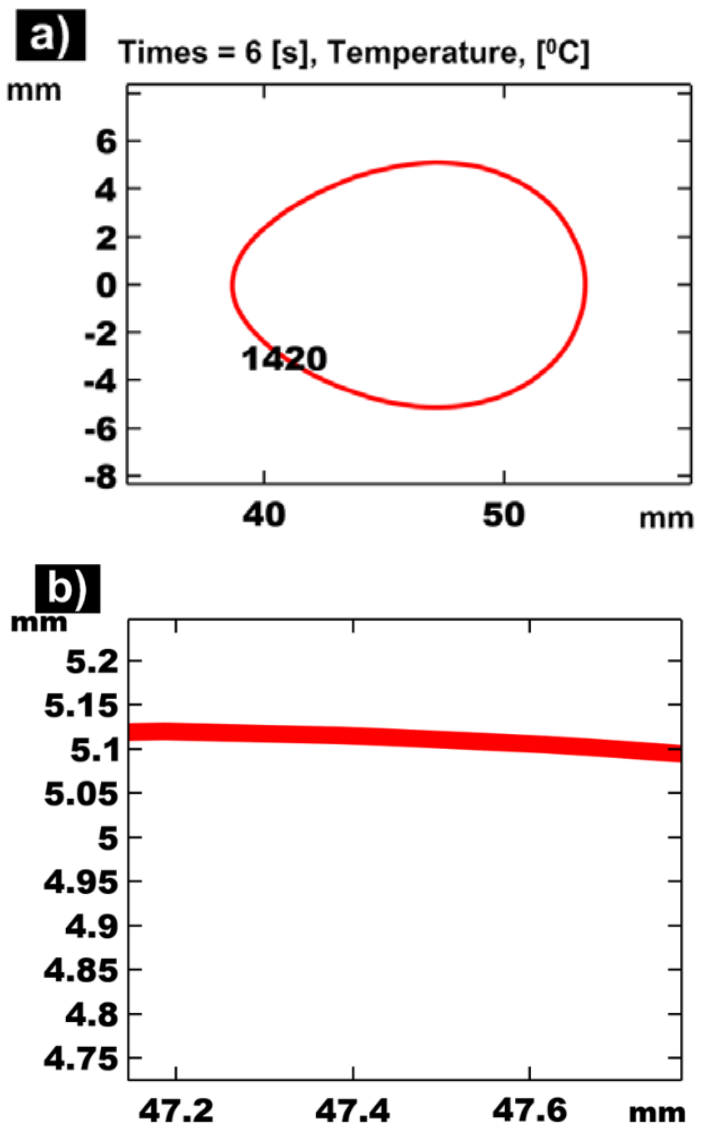

Fig.2. Determination of the maximum width of the seam by the isotherm of the solidus on the upper surface of the welded specimen

To check the sensitivity of the solution with respect to the thermal properties of the base metal, the temperature cycles obtained from two solutions were compared (Fig. 6). The first of them has temperature-dependent material characteristics (Fig. $7 \div$ Fig. 9), and the second is with constant values of the thermal properties: thermal conductivity $\lambda=36[\mathrm{~W} /(\mathrm{m} . \mathrm{K})]$; specific heat capacity at constant pressure $\mathrm{Cp}=660[\mathrm{~J} /$ (kg.K)]; density $\rho=7740$ [kg / m3]. The considered temperature cycles are shown in Fig. 10 and Fig. 11, respectively.

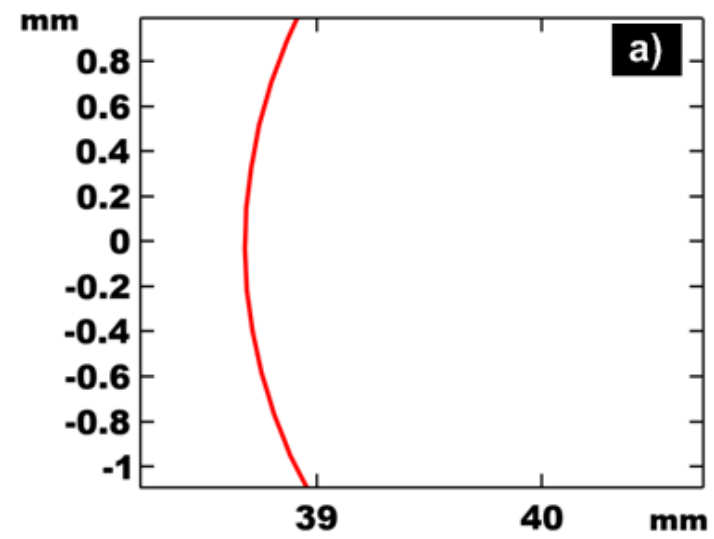




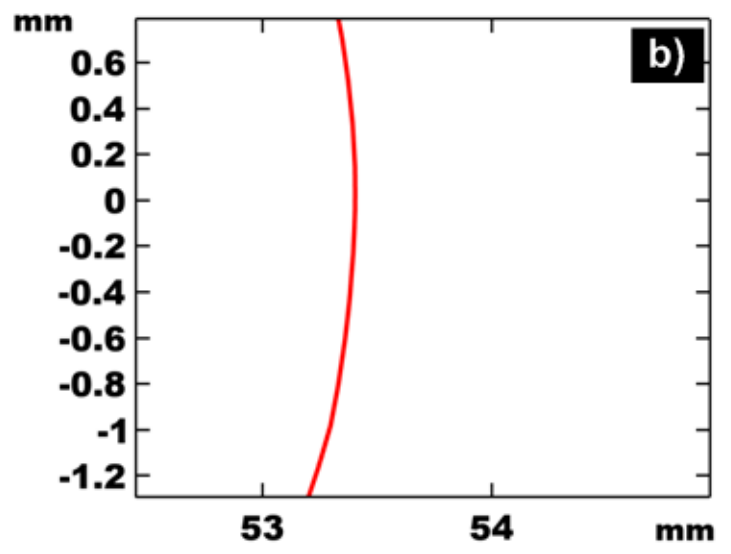

Fig.3. Determination of the length of the weld pool crystallizing front of the weld pool (a) and melting front (b).

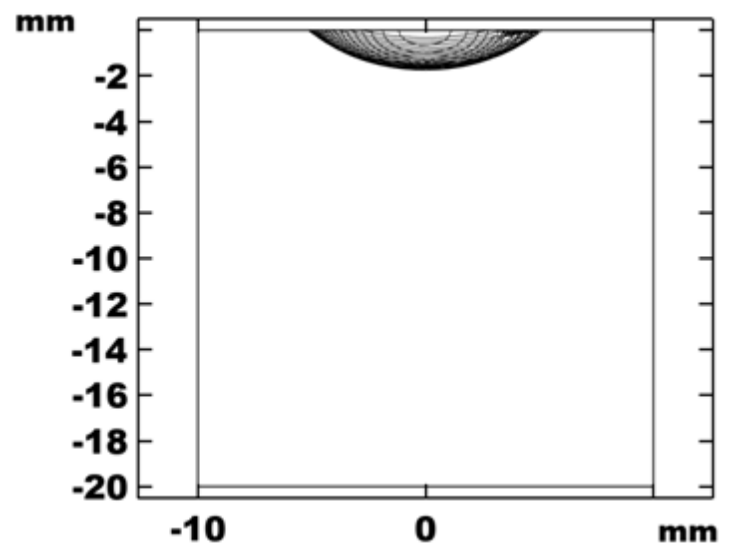

Fig.4. Isotherms in planes perpendicular to the seam axis for the solidus temperature in the weld pool range.

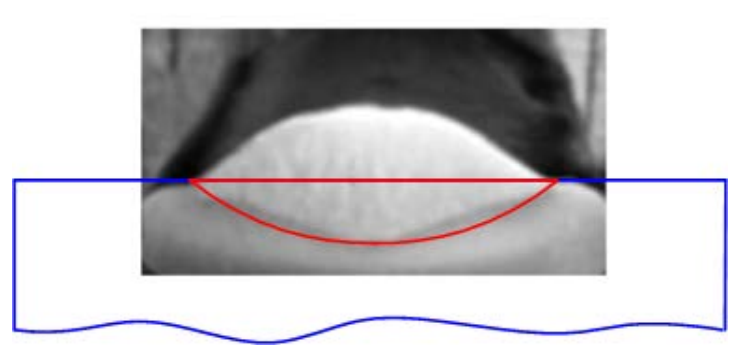

Fig.5. Comparison of the experimental and calculated form of the penetration.

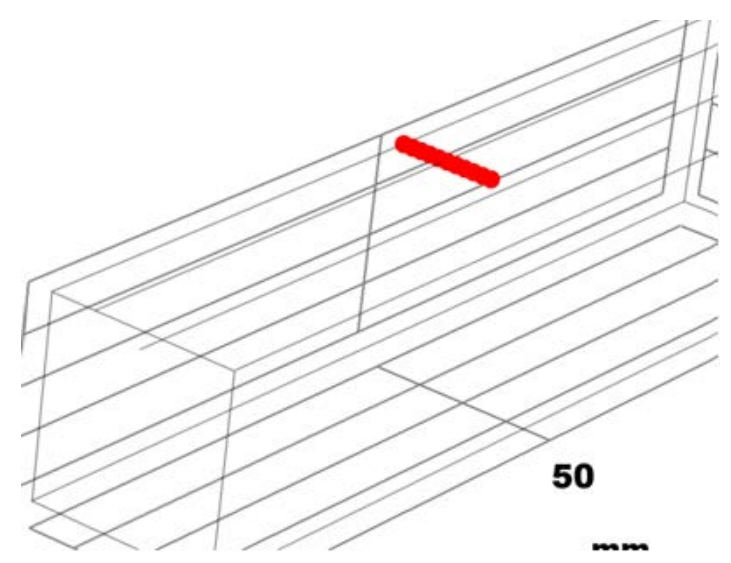

Fig.6. Control points for sensitivity analysis.

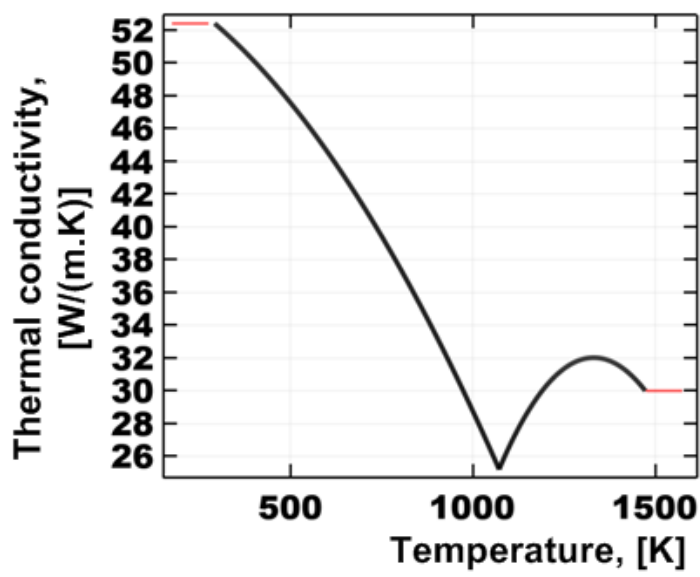

Fig.7. Base material properties - thermal conductivity.

Fig. 12 shows the square of the relative error. It can be seen that $\delta \leq 0.095$. The RMS error is calculated as

$$
\varepsilon=\frac{1}{N} \sqrt{\sum_{i=1}^{N}\left(1-\frac{T_{2 i}}{T_{i}}\right)^{2}}
$$

Here $\mathrm{N}$ is the number of time points for which the comparison is performed, and $i$ is the sequence number of that moment. We must emphasize that the comparison should not be made for the entire period of the welding process, but only for the time interval in which the temperature change of interest takes place. The obtained results are given in table 4 and visualized in fig.13. 
Environment. Technology. Resources. Rezekne, Latvia Proceedings of the $13^{\text {th }}$ International Scientific and Practical Conference. Volume 3, 357-362

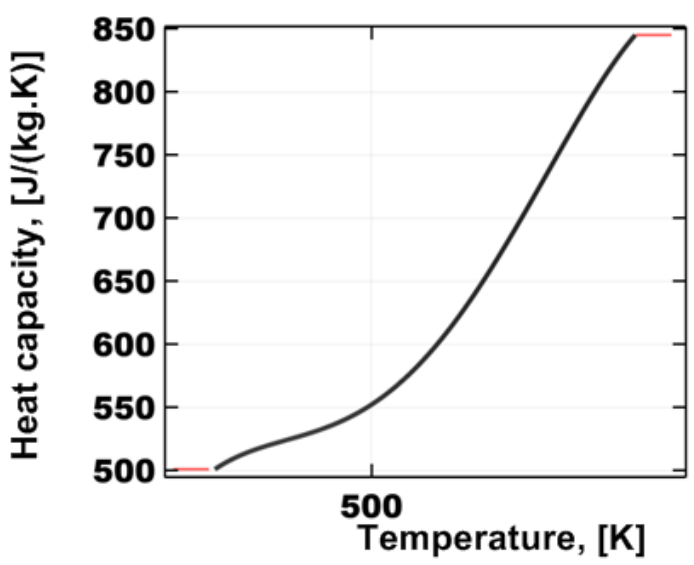

Fig.8. Base material properties - heat capacity at constant pressure.

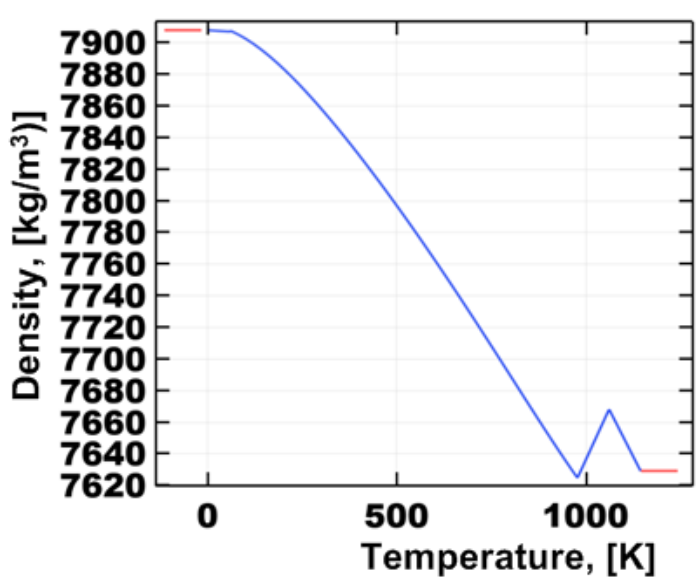

Fig.9. Base material properties - density.

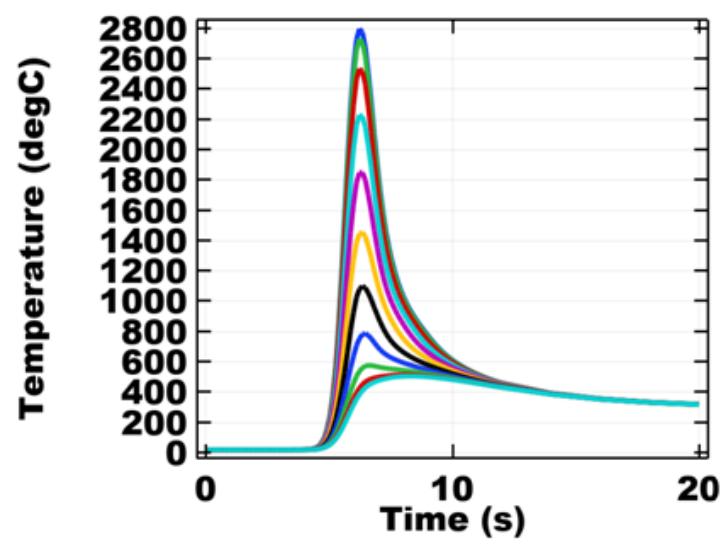

Fig.10. Temperature cycles taking into account the temperature dependence of the thermal properties.

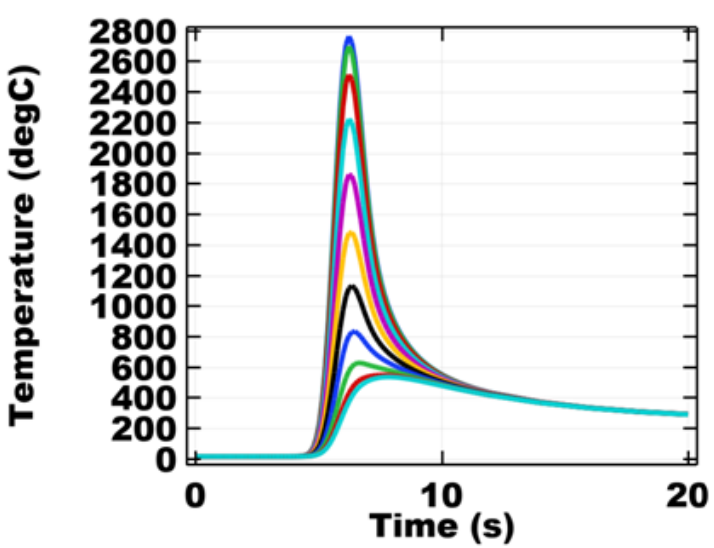

Fig.11. Temperature cycles at constant values of thermal properties.

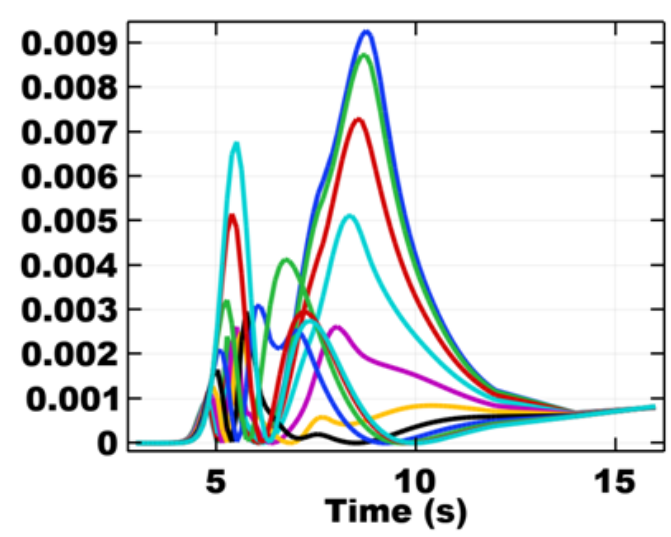

Fig.12. Changes in the square of the relative error over time for different points on the sample surface.

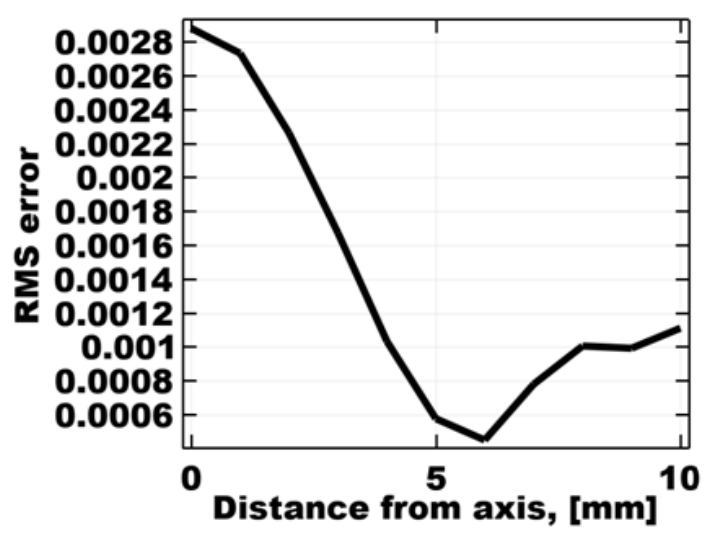

Fig.13. RMS error depending on the distance to the seam axis.

\section{CONCLUTIONS.}

A new heat source model for GMAW has been proposed. It is shown that the heat source can be calibrated for the conditions of MIG / MAG welding. An analysis of the sensitivity of the heat transfer model to the thermal properties of the base metal was performed. The maximum value of the error obtained when using constant values of 
the material characteristics is $9.5 \%$. The root mean square error in this case is not more than $0.28 \%$. The model describes very well the weld in terms of its width and depth, but when an inflection point is formed in penetration profile, the deviation can become significant - in this case a heat source model should be used, taking into account the processes in the key-hole.

TABLE IV. RMS ERROR DEPENDING ON THE DISTANCE TO THE SEAM AXIS.

\begin{tabular}{|c|c|c|c|}
\hline $\mathbf{y},[\mathbf{m m}]$ & $\boldsymbol{\varepsilon}$ & $\mathbf{y},[\mathbf{m m}]$ & $\boldsymbol{\varepsilon}$ \\
\hline 0 & $2.88 \mathrm{E}-03$ & 6 & $4.53 \mathrm{E}-04$ \\
\hline 1 & $2.74 \mathrm{E}-03$ & 7 & $7.83 \mathrm{E}-04$ \\
\hline 2 & $2.27 \mathrm{E}-03$ & 8 & $1.01 \mathrm{E}-03$ \\
\hline 3 & $1.68 \mathrm{E}-03$ & 9 & $9.95 \mathrm{E}-04$ \\
\hline 4 & $1.04 \mathrm{E}-03$ & 10 & $1.11 \mathrm{E}-03$ \\
\hline 5 & $5.80 \mathrm{E}-04$ & & \\
\hline
\end{tabular}

\section{REFERENCES}

[1] do Nascimento, A.S., de Menezes Jr., L.C., Vilarinho, L.O., Effect of waveform and shielding gas on melting rate and bead geometry for MIG/MAG-PV [Efeito do formato de onda e gás de proteção sobre a taxa de fusão e geometria do cordão na soldagem MIG/MAG-PV], (2012) Soldagem e Inspecao, 17 (1), pp. 40-48, ISSN: 01049224, DOI: 10.1590/S0104-92242012000100007.

[2] Katayama, T., Tashiro, S., Tanaka, M., Improvement of bead formation of plasma MIG welding in pure argon atmosphere, (2011) Yosetsu Gakkai Ronbunshu/Quarterly Journal of the Japan Welding Society, 29 (3), pp. 39s-42s, ISSN: 02884771, DOI: $10.2207 /$ qjjws.29.39s

[3] Tong, H., Ueyama, T., Ushio, M., Study on phenomena of wire melting and bead formation in AC pulsed MIG welding, (2004) Yosetsu Gakkai Ronbunshu/Quarterly Journal of the Japan Welding Society, 22 (3), pp. 389-397, ISSN: 02884771, DOI: 10.2207/qjjws.22.389.

[4] Yamamoto, H., Harada, S., Ueyama, T., Ogawa, S., Development of Low Frequency Pulsed MIG Welding Process for Al and its alloy Study on Low Frequency Pulsed MIG Welding Process (Report 1), (1992) QUARTERLY JOURNAL OF THE JAPAN WELDING SOCIETY, 10 (2), pp. 233-238, ISSN: 02884771, DOI: 10.2207/qijws.10.233

[5] Maruo, H., Hirata, Y., Noda, Y., Effects of Welding Current Waveform on Metal Transfer and Bead Formation in Pulsed MIG Welding-Study on Pulsed Arc Welding (Report 1)-(1984) QUARTERLY JOURNAL OF THE JAPAN WELDING SOCIETY, 2 (1), pp. 12-18. ISSN: 02884771, DOI:10.2207/qjjws.2.12

[6] Ando, K., Nishikawa, J., Inoue, M., Phenomena of the Molten Pool at High Current and High Speed Mig Welding, (1971) JOURNAL OF THE JAPAN WELDING SOCIETY, 40 (4), pp. 307-311, ISSN: 00214787, DOI: 10.2207/qjjws1943.40.307

[7] Toshiyasu, F., Yoshihiko, S., Shiro, T., Effects of nitrogen, oxygen and hydrogen gases added to argon gas on mig-welding of aluminum alloys, (1968) Journal of Japan Institute of Light Metals, 18 (12), pp. 609-616, ISSN: 04515994, DOI: 10.2464/jilm.18.609

[8] Zuo, S., Wang, Z., Wang, D., Du, B., Cheng, P., Yang, Y., Zhang, P., Lang, N.,Numerical simulation and experimental research on temperature distribution of fillet welds, (2020) Materials, 13 (5), art. no. 1222, ISSN: 19961944, DOI: 10.3390/ma13051222

[9] Bai, Q., Ma, Y., Xing, S., Chen, Z., Kang, X., Prediction of the temperature distribution and microstructure in the HAZ of sa508gr4 reactor pressure vessel steel, (2017) ISIJ International, 57 (5), pp. 875-882, ISSN: 09151559, DOI: 10.2355/isijinternational.ISIJINT-2016-321

[10] Pamnani, R., Vasudevan, M., Jayakumar, T., Vasantharaja, P. Ganesh, K.C., Numerical simulation and experimental validation of arc welding of DMR-249A steel, (2016) Defence Technology, 12 (4), pp. 305-315, ISSN: 22149147, DOI 10.1016/j.dt.2016.01.012

[11] Ismail, M.I.S., Afieq, W.M.A., Thermal analysis on a weld joint of aluminium alloy in gas metal arc welding, (2016) Advances in Production Engineering and Management, 11 (1), pp. 15-28, ISSN: 18546250, DOI: 10.14743/apem2016.1.207

[12] Bjelić, M.B., Kovanda, K., Kolarik, L., Vukićević, M.N. Radičević, B.S., Numerical modeling of two-dimensional heattransfer and temperature-based calibration using simulated annealing optimization method: Application to gas metal arc welding, (2016) Thermal Science, 20 (2), pp. 655-665, ISSN: 03549836, DOI: 10.2298/TSCI150415127B

[13] Liu, H., Niu, L., Finite element simulation research on medium plate multi-pass welding temperature field, (2015) Open Mechanical Engineering Journal, 9 (1), pp. 786-790, ISSN: 1874155X, DOI: $10.2174 / 1874155 X 01509010786$

[14] Liskevych, O., Scotti, A., Determination of the gross heat input in arc welding, (2015) Journal of Materials Processing Technology, 225 $\quad$ pp. $139-150, \quad$ ISSN: 09240136 , DOI:10.1016/j.jmatprotec.2015.06.005

[15] Yoshihiro, T., Manabu, T., Numerical Simulation of heat source property with metal vapor behavior in GMA Welding, (2012) Yosetsu Gakkai Ronbunshu/Quarterly Journal of the Japan Welding Society, 30 (1), pp. 68-76, ISSN: 02884771, DOI: 10.2207/qjjws.30.68

[16] Lidam, R.N., Yupiter, H.P.M., Redza, M.R., Rahim, M.R. Sulaiman, M.S., Zakaria, M.Y., Thama, G., Abasa, S.K., Haruman, E., Chau, C.Y., Simulation study on multipassed welding distortion of combined joint types using thermo-elastic-plastic FEM, (2012) Journal of Engineering Research, 9 (2), pp. 1-16, ISSN: 17266009, DOI: 10.24200/tjer.vol9iss2pp1-16

[17] Yamane, S., Yamazaki, T., Kaneta, T., Nakajima, T., Yamamoto, $\mathrm{H}$., Experiment and numerical simulation in temperature distribution and welding distortion in GMA welding, (2011) Yosetsu Gakkai Ronbunshu/Quarterly Journal of the Japan Welding Society, 29 (3), pp. 31s-34s, ISSN: 02884771, DOI: 10.2207/qjjws.29.31s

[18] Mathieu TERNER, Tsend-Ayush BAYARSAIKHAN, Hyun-Uk HONG and Je-Hyun LEE Influence of Gas Metal Arc Welding Parameters on the Bead Properties in Automatic Cladding, Journal of Welding and Joining Volume 35 Issue 1 pp.16-25 (2017) ISSN: 2466-2232. Online ISSN: 2466-2100, https://doi.org/10.5781/JWJ.2017.35.1.16

[19] Peter Petrov, Manahil Tongov, Numerical modelling of heat source during electron beam welding, Vacuum 171 (2020) 108991, ISSN: 0042-207X, https://doi.org/10.1016/j.vacuum.2019.108991

Acknowledgments:

This work was made possible by a project KP-06-N37/31, funded by the NSF. 